\title{
ASSESSMENT AND MONITORING OF AESTHETIC APPEARANCE OF BUILDING BIOMATERIALS DURING THE SERVICE LIFE
}

\author{
ANNA SANDAK $K^{1,2}$, JAKUB SANDAK $^{1,2}$, ATHANASIOS DIMITRIOU $^{3}$, INGUNN BURUD ${ }^{4}$, \\ THOMAS THIIS ${ }^{4}$, LONE ROSS GOBAKKEN ${ }^{5}$, GRAHAM ALAN ORMONDROYD ${ }^{3} \&$ \\ DIMITRIOS KRANIOTIS ${ }^{6}$ \\ ${ }^{1}$ Trees and Timber Institute CNR-IVALSA, San Michele All'Adige, Italy \\ ${ }^{2}$ University of Primorska, Slovenia \\ ${ }^{3}$ BioComposites Centre, Bangor University, UK \\ ${ }^{4}$ Norwegian University of Life Sciences NMBU, Norway \\ ${ }^{5}$ Norwegian Institute of Bioeconomy Research NIBIO, Norway \\ ${ }^{6}$ Oslo and Akershus University College of Applied Sciences, Norway
}

\begin{abstract}
Bio-based building materials offer a wide range of outlooks, from traditional rustic to modern design products. Recent development in the science of materials significantly improves their functional performance. However, when considering the use of bio-materials in outdoor environments, materials will deteriorate due to processes like weathering, oxidation, biodegradation, wear, and decay. Consequentially, biomaterials may lose visual appeal, leading to a perceived need for replacement even if the material is far from reaching functional failure. Visual assessment is the most direct method for evaluation of the aesthetic appearance of materials. However, it possesses a high degree of subjectivity when performed by an untrained person. On the contrary, measurement of surface properties with dedicated sensors provides objective values that might be related to the current state of the material in use. Recent developments in field of optics and electronics opens a new possibility to perform measurements in-situ. Colour-, gloss-, or spectro-photo-meters allow non-destructive measurements without particular sample preparation. Since all of the above techniques provide complementary information, the multi-sensor approach is more frequently suggested for applied research. The material state can be assessed regularly during service life. In this case, such measurement turns into monitoring. The paper illustrates examples of assessment and monitoring of biomaterials' degradation due to weathering. Direct implementation of various sensors is demonstrated. A proposal for the approach of combining data provided by various sensing techniques with data mining is also presented.
\end{abstract}

Keywords: biomaterials for buildings, aesthetics, service life, weathering, surface characterization.

\section{INTRODUCTION}

The trend for increased use of novel material solutions at reduced-costs through predictive design of materials and innovative production technologies is observed currently. As a consequence, higher numbers of well performing (also in severe environments) construction materials are available on the market. The expansion of bio-based products availability and its wide utilization in modern buildings is a derivative of the Europe Union strategies to reduce greenhouse gas emissions. It is estimated that bio-materials will play progressively more significant role in the future, in order to assure the full sustainability of the construction sector. As a result, a number of applications of wood and other bio-based materials as construction and façades elements are increasing. These materials are often chosen due to low maintenance cost, simple processing and easy accessibility [1]. However, an important issue when dealing with external applications is their technical performance and aesthetic expression during service life. Building elements are often exposed to mechanical, environmental and biological alterations during their use phase. The 
most susceptible parts are unprotected surfaces since they are most subjected to ageing, weathering or decay.

Consistent determination of durability and service life of materials, components, installations, structures and buildings become extremely important in the modern construction industries [2]. Service life is defined here as the period of time after construction in which a structure maintains or exceeds minimum performance requirements without unforeseen or extraordinary maintenance or repair [3]. In the real cases service life of building components is finished not because they have lost ability to perform, but because there is no longer appreciation of them in their original form [4]. Moreover, the aesthetic requirements are normally reached before functional failure and reduction of safety level, therefore many building elements reach the end of life for aesthetic reasons [5].

The characteristic grey patina is appearing on the weathered ligno-cellulosic materials surface already after few months of exposure. Small cracks, discontinuities, erosion and mould growth are other aspects noticeable even by a non-expert person. The degradation kinetics are depending not only by the specific climatic conditions but also due to the type

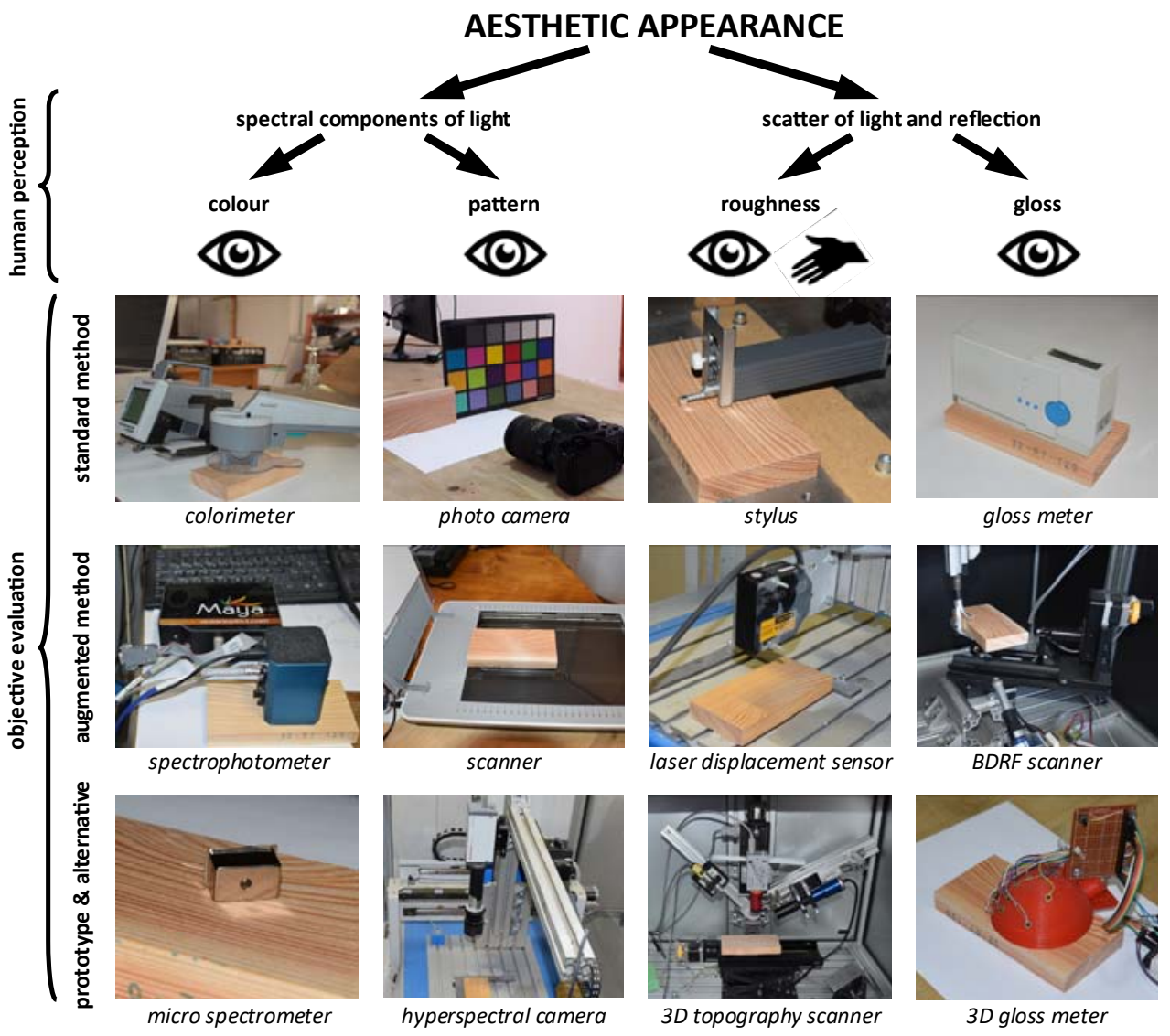

Figure 1: Quantification of the aesthetic appearance of surfaces with human perception and sensors (objective evaluation). 
of the applied materials and architecture elements. In most cases weathering causes only superficial changes and principally affects the aesthetic or visual appearance of building. However, even minor cracks might act as penetration path for water. In consequence, further deterioration of bulk biomaterial by fungi is expected within a short period of time [6].

The simplest, but most frequently used, method for evaluation of the surface structure is by means of human inspection. Sight and touch senses are mostly involved in the perception, by assessing different aspects and impressions. These human perceptions are schematically summarized in Fig. 1 where the aesthetic appearance is associated with the colour, pattern, roughness and gloss. These factors are appraised with human perception, but the aesthetic appearance can also alternatively be evaluated with dedicated sensors [7]. These are in fact mimicking human perception (vision and/or tactile), but in contrast to the subjective human grading, they provide objective quantification of the surface state. An example of sensing techniques suitable for evaluation of aesthetic appearance is listed in Fig. 1 assuming different levels of measurement/data complexity. The quantifiers provided by each technique are briefly summarized in Table 1, highlighting diverse typologies of the results.

Visual assessment of weathered surfaces can be executed with a certain frequency, even if it may be problematic to assure consistent objectivity of the human grading. For that reason, the substitution of a trained expert with electronic sensors is encouraged for evaluation purposes nowadays [8]. Sensor-based evaluation and its systematic implementation along the service life, defined here as a monitoring, has become a routine

Table 1: Type of data provided by sensors assessing aesthetical surface properties.

\begin{tabular}{|c|c|c|c|}
\hline Colorimeter & Photo camera & Stylus & Gloss meter \\
\hline $\begin{array}{l}\text { - Colour coordinates } \\
\text { (CIE Lab, RGB, HIS) }\end{array}$ & $\begin{array}{l}\text { - Colour image of } \\
\text { surface }\end{array}$ & $\begin{array}{l}\text { - Surface } \\
\text { roughness profile } \\
\text { - Surface } \\
\text { roughness } \\
\text { parameters }\end{array}$ & $\begin{array}{l}\text { - One direction } \\
\text { reflectance }\end{array}$ \\
\hline Spectrometer & Scanner & $\begin{array}{l}\text { Laser displacement } \\
\text { sensor }\end{array}$ & $3 D$ gloss meter \\
\hline $\begin{array}{l}\text { - Reflectance } \\
\text { spectrum } \\
\text { - Colour coordinates }\end{array}$ & $\begin{array}{l}\text { - Well spatially } \\
\text { defined image of } \\
\text { surface }\end{array}$ & $\begin{array}{l}\text { - Surface } \\
\text { roughness profile } \\
\text { measured without } \\
\text { contact } \\
\text { - Surface } \\
\text { roughness } \\
\text { parameters }\end{array}$ & $\begin{array}{l}\text { - Reflectance to } \\
\text { several directions }\end{array}$ \\
\hline Microspectrometer & $\begin{array}{l}\text { Hyperspectral } \\
\text { camera }\end{array}$ & $\begin{array}{l}3 D \text { topography } \\
\text { scanner }\end{array}$ & BDFR gloss meter \\
\hline $\begin{array}{l}\text { - Reflectance } \\
\text { spectrum in different } \\
\text { ranges (UV-VIS-NIR) } \\
\text { measured over very } \\
\text { small area }\end{array}$ & $\begin{array}{l}\text { - Spectral map of } \\
\text { surface } \\
\text { - Detailed map of } \\
\text { colour coordinates }\end{array}$ & $\begin{array}{l}\text { - Map of surface } \\
\text { irregularities } \\
\text { - Surface area } \\
\text { roughness } \\
\text { parameters }\end{array}$ & $\begin{array}{l}\text { - Bi-directional } \\
\text { reflectance } \\
\text { function (BDRF) } \\
\text { for a given spatial } \\
\text { position and light } \\
\text { wavelength }\end{array}$ \\
\hline
\end{tabular}


tool for detecting material changes and for quantify the degradation processes. Nondestructive testing (NDT) techniques, among other methods, become particularly useful for building monitoring. These require limited number of samples, and in case of portable instruments also allows performing of measurement directly on-site. Likewise, Internet of Things (IoT) solutions based on wireless sensors, network control systems and real-time data acquisitions allows even more efficient data procurement and advanced monitoring of building performance [9].

Sensors and data acquisition solutions originally developed for NDT inspections were adapted for monitoring purposes in a number of diverse applications, including the construction sector [10]. Combining multiple sensors simultaneously for monitoring of buildings is a favourable configuration due to better representation of real-life cases. However, multi-sensor monitoring generates new problems and challenges, as the proper combination of different sources of information is fundamental [11]. Consequently, selection of an optimal sensor, measurement strategy, signal processing and interpretations of results are more complex and demanding [8], [12]. It is important to mention that proper system configuration, reliable data collection and interpretation of results requires both: understanding of the mechanisms of monitored process and the technical details of the technologies behind the monitoring system (such as selection of proper sensors/transducers, electronics, signal processing, data mining and visualisation) [13].

The goal of this work was to review state-of-the-art technological solutions suitable for objective assessment of bio-materials used in modern buildings exterior, with a special focus on the aesthetics. Another objective was to present a concept and methodology for determination of a simple qualifier describing the degradation extent due to natural weathering.

\section{MATERIALS AND METHODS}

\subsection{Experimental samples}

Experimental samples used for demonstration of the aesthetical deterioration of biomaterials due to weathering were prepared from one piece of Norway spruce (Picea abies L. Karst.) wood. The thickness of samples was $5 \mathrm{~mm}$ and the exposed to weathering surface was $30 \times 35 \mathrm{~mm}$ (width x length respectively).

\subsection{Weathering tests}

Natural weathering test was conducted in San Michele All/Adige, Italy (46 $\left.12^{\prime} \mathrm{N} 11^{\circ} 8^{\prime} \mathrm{E}\right)$. Set of 12 samples was placed on a building roof at $45^{\circ}$ to the horizon facing the South. The test started in July 2014 and samples were collected monthly for a period of 1 year. Additionally, one sample was stored in a dark climatic chamber during whole duration of the test and served as a reference. Experimental samples after collection were also conditioned in the dark, climatic chamber $\left(20^{\circ} \mathrm{C}, 60 \% \mathrm{RH}\right)$ to the equilibrium moisture content of $\sim 12 \%$.

\subsection{Visual evaluation}

Each sample was assessed by a group of independent experts after sample conditioning. The presence of surface defects, such as discoloration, raised fibres, cracks, splits, 
delamination, erosion or moulds etc. was evaluated. All samples were assessed at the same time but in the random order. The quality grade was provided for each sample as a subjective evaluation. The ranking scale ranged from 0 to 7 , where grade " 0 " corresponded to the superior quality surface, and not acceptable quality was considered as grade "7".

\subsection{Sensory evaluation}

A set of the following techniques (corresponding to that listed in Fig. 1) was implemented for the objective evaluation of the surface conditions after natural weathering:

\subsubsection{Colorimeter}

The surface colour coordinates were scrutinized with a DataColor Microflash ${ }^{\circledR}$ colorimeter according to the routine procedure. The light source used for computation of the CIE Lab indicators was D65 and the viewing angle was $10^{\circ}$. The sensor calibration was carried out with the white and black standards provided by the supplier. Each sample was measured five times. The standard deviation of such measurement was considered as an indicator of the instrument reliability and texture variability of the material.

\subsubsection{Spectrophotometer}

The standardized colour parameters were estimated on the base of the spectra measured by a Maya2000 (Ocean Optics) spectrometer equipped with an integrating sphere. The selected illuminant was D65 and viewer angle was $10^{\circ}$. The light source was both halogen and deuterium, allowing measuring spectra in the range from UV up to NIR (200-1200nm). The sensor calibration was carried out with the same white and black standards as used for the DataColor colorimeter. The colour was characterized according to the CIE Lab system, with three independent parameters $(L, a$ and $b)$ computed from the averaged spectrum.

\subsubsection{Scanner}

Digital colour images of sample surfaces were collected after the weathering campaign and samples conditioning by a HP G2710 office scanner. All the images were acquired with a resolution of 300 DPI. Custom image processing algorithms were developed in LabView Vision (National Instruments). The colour histograms and average colours in RGB and HSI spaces were computed for each sample. The surface defects detection modules were also developed in order to quantify the weathered surface quality.

\subsubsection{Hyperspectral imaging camera}

A prototype of the hyperspectral system, described by Sandak et al. [14], was used for CIE Lab colour mapping of the weathered samples. The optical system consisted of spectrograph (Specim V10), high sensitivity CCD camera (Hamamatsu ORCA-5) and telecentric lenses (Computar TEC-55). The light source was a halogen bulb emitting light that covers the whole spectral band of the spectrograph. The movement of the hyperspectral system over the measured sample was performed by means of the laboratory CNC machine. The samples were placed on the machine table, then the optical system being mechanically connected with the light source was moved over the measured surface. The computer controlled the motion, triggered the camera and collected data. The data, in a form of 12-bit monochromatic images, were stored on the hard disk and were post-processed on the external server. Custom software was developed for both the hyperspectral data acquisition and post-processing. 


\subsubsection{Gloss}

A REFO 60 instrument (DrLange) with an angle of incidence of $60^{\circ}$ was used for measuring surface gloss. Five measurements in two directions (perpendicular and along the grain) were performed on random locations over the surface of each sample.

\subsubsection{Laser displacement sensor}

The surface roughness was measured by means of laser displacement sensor LK-G32 (Keyence) installed on the laboratory CNC machine. Five profiles were scrutinized on each sample in order to quantify wood erosion.

\section{RESULTS AND DISCUSSION}

Images of the wood samples after natural weathering in different periods of exposure are presented in Fig. 2. A clear change of the appearance is evident already after three months of exposure. Samples exposed longest had the darkest colour. This observation can be confirmed by analysis of the CIE Lab colour coordinates measured with colorimeter, as summarized in Fig. 3. The drop of lightness $\left(C I E L^{*}\right)$ is very high after first month of weathering and the surface becomes darker along the test duration. The progress of CIE $a^{*}$ and $C I E b^{*}$ is slightly different as the colour coordinates increase dramatically in the first month, and systematically decrease afterward.

Similar trend is noticeable for the surface gloss, both for parallel and perpendicular directions (Fig. 3). An increase of the glossiness after one-month weathering corresponds to washing out tiny cell wall structures/particles damaged during surface preparation (cutting), where the following decrease of gloss may be associated with micro-cracking, erosion and roughening of the surface.

It is also apparent by observing weathered wood images that the colour change within late- and early- wood zones differs significantly. Space-resolved hyperspectral imaging can be used therefore for more detailed description of the colour distribution. Consequently, it becomes possible to characterize the colour of latewood and earlywood distinctly. In Fig. 4 it is shown where no-weathered wood is very light $(C I E L>80)$, the difference between late and early wood was very minor. The lightness decreases with the weathering duration, making the difference between late and early wood much more pronounced.

The change of colour (and gloss) is not the only effect of the natural weathering of biomaterials. Due to organic origin and high variability with bulk properties (anatomical complexity, chemical/physical anisotropy, heterogeneity), the reaction of the materials to degrading factors is space dependant. This is clearly noticeable in Fig. 5, where surface topography profiles, measured with laser displacement sensor are presented. The surface of wood not exposed to the weathering is relatively smooth, with the height irregularities range of $\sim 50 \mu \mathrm{m}$. The profile outline become more distorted along the weathering period with a clear deepening in the zones of earlywood. Erosion presence is already evident after 3 months of weathering, being most profound $(>400 \mu \mathrm{m})$ after one year of natural weathering. It is also clear that the kinetics of the erosion of latewood was negligible, when compare to earlywood.

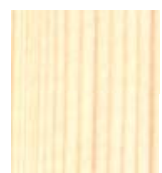

O months

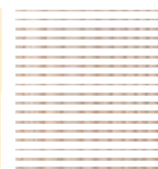

3 months

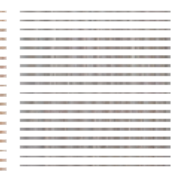

6 months

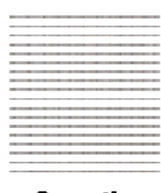

9 months

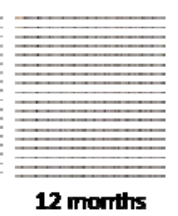

Figure 2: Appearance of wood samples exposed to natural weathering after different periods of time (San Michele, Italy, June 2014 - June 2015, South). 

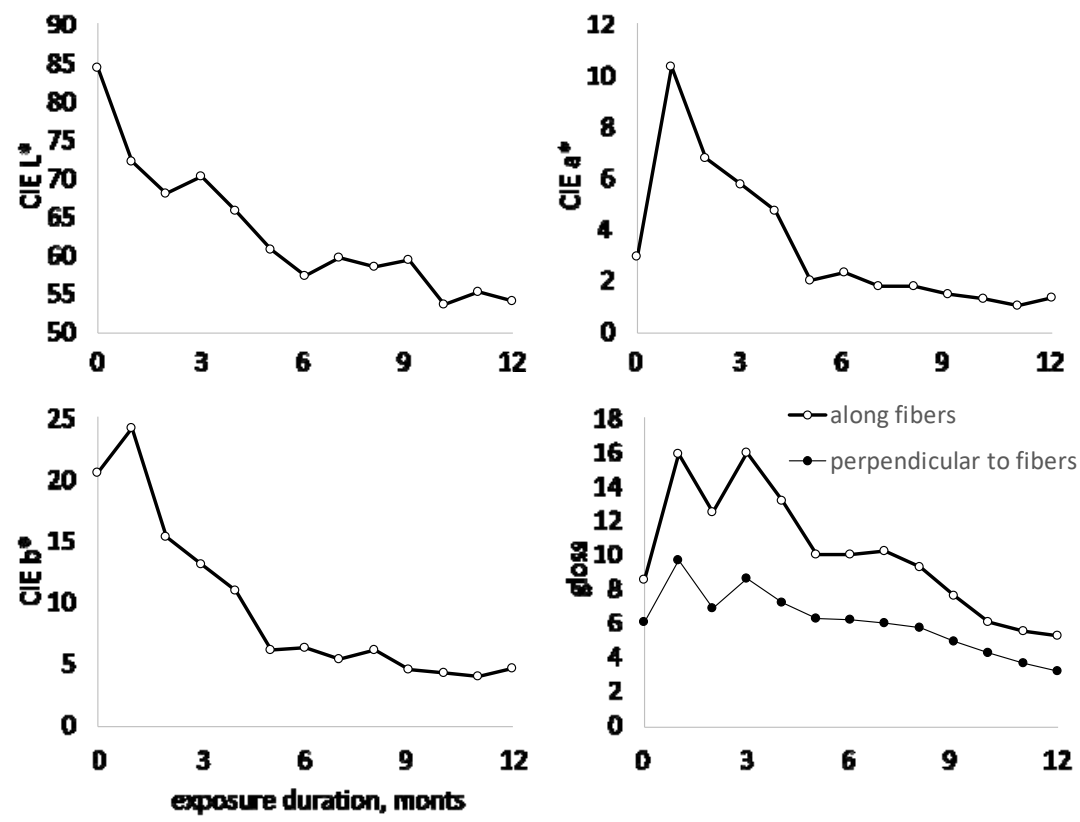

Figure 3: Change of average colour coordinates and gloss of Norway spruce wood during natural weathering.

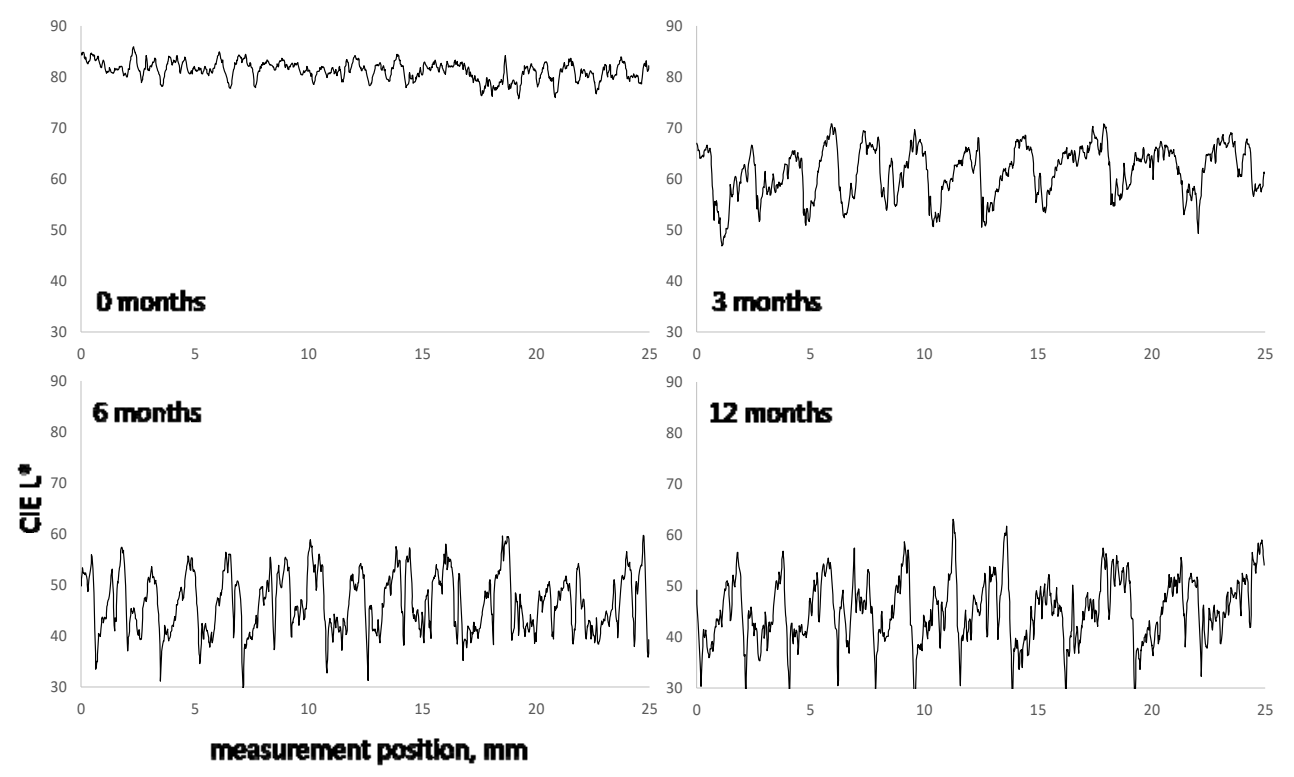

Figure 4: Colour lightness (CIE L*) profiles assessed with hyperspectral imaging camera on Norway spruce wood samples exposed to natural weathering for different periods of time. 


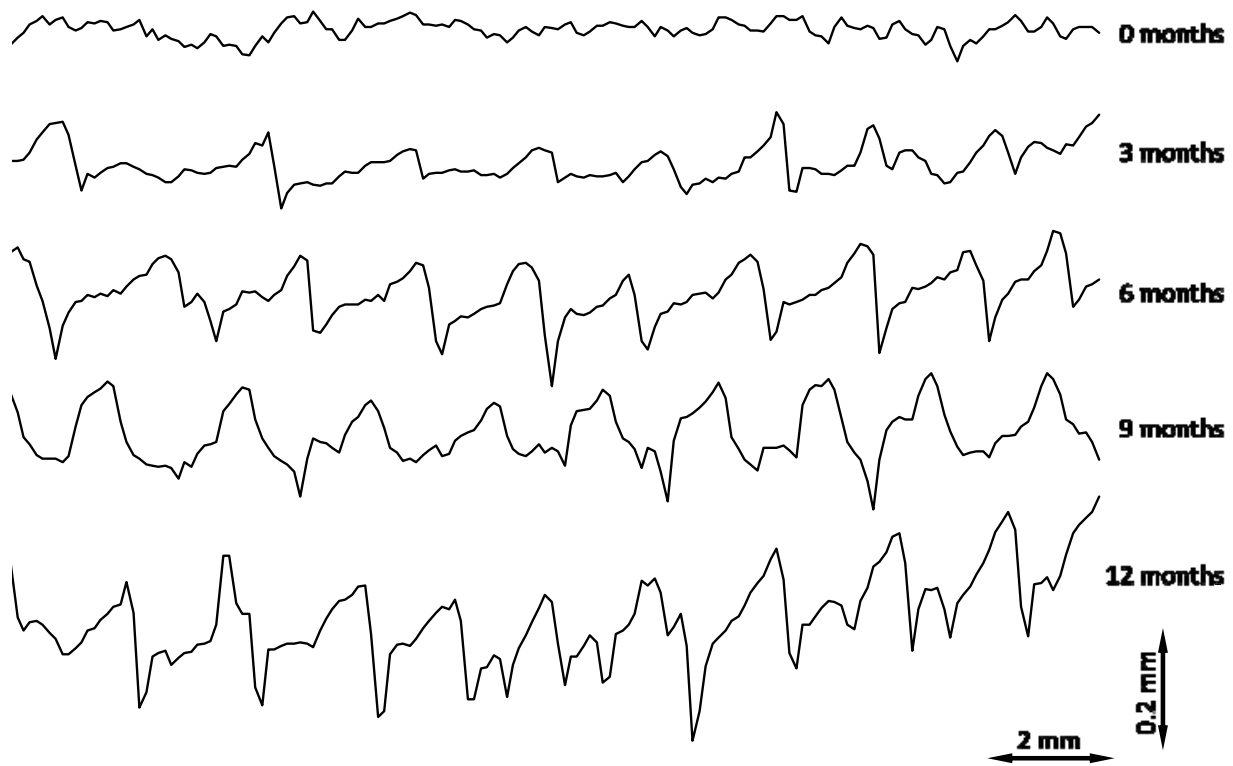

Figure 5: Erosion of Norway spruce wood surface along the progress of weathering assessed as a surface topography profiles.

Each of the above surface state quantifiers alone provide a noteworthy information, but none is an ultimate parameter/descriptor of the weathering progress. It is therefore necessary to combine several indicators together in order to generalize the material status and filter out (minimize) the result variability. The concept for calculation of "weathering coefficient" was previously presented by Sandak et al. [8]. The custom algorithm for multisensory data fusion and computation of a weathering indicator normalizes the raw data (parameters) $p_{i}$ as obtained by each sensor $i$ and summarises these, considering their importance (weight) $w_{i}$. The $W_{\text {ind }}$ computation algorithm is mathematically expressed in eqn 1:

$$
W_{\text {ind }}=\frac{\sum w_{i} \cdot p_{i}}{\sum w_{i}}
$$

The resulting $W_{\text {ind }}$ can be considered as a weighted average indicating the state of the surface degradation, where $W_{\text {ind }}=0$ corresponds to a non-weathered sample and $W_{\text {ind }}=1$ to its terminal state. The weathering indicator method is a simple technique usable to combine information from various sources. An example of the weathering index computed for the parameters as presented in Figs 2 to Fig. 5 is shown below. The nearly monotonic increase of the $W_{\text {ind }}$ is noticeable in Fig. 6, what closely corresponds to the quality grade provided by the expert person.

The quantitative description of the surface degradation progress along the weathering duration is a required step for the numerical model development. The overall concept for deterioration modelling approach is presented in Fig. 7, where weathering index is one of the variables influencing computation. The other input to the model is a weather dose, 
computed on the base of climate data, local circumstances and technical/architectural solutions implemented in the modelled object.

\section{CONCLUSIONS}

Weathering of biomaterials used externally in constructions is an important issue affecting the performance of the building and the customers' satisfaction. The surface deterioration is unavoidable, but its negative impact can be minimized by proper maintenance or replacements. A reliable model of the weathering would be of a great help in this regard. Our article proposes a base for such model development, and it also discuss and provides objective assessment of the surface state by means of multisensory approach. A proposal for implementation of specific measurement techniques optimal for evaluating certain quality aspects is presented with some examples. The computation of weathering index, even if very simple as a concept, is a reliable approach closely correlated to the grading performed by an expert person.

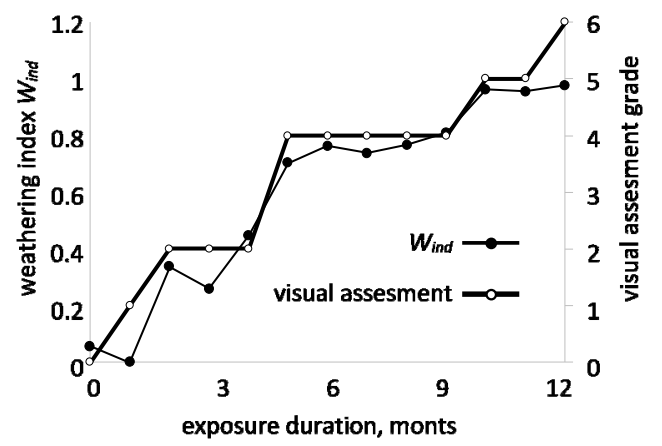

Figure 6: Progress of weathering computed as weathering index on the base of surface characteristics measured with sensors and visual grading according to an expert person.

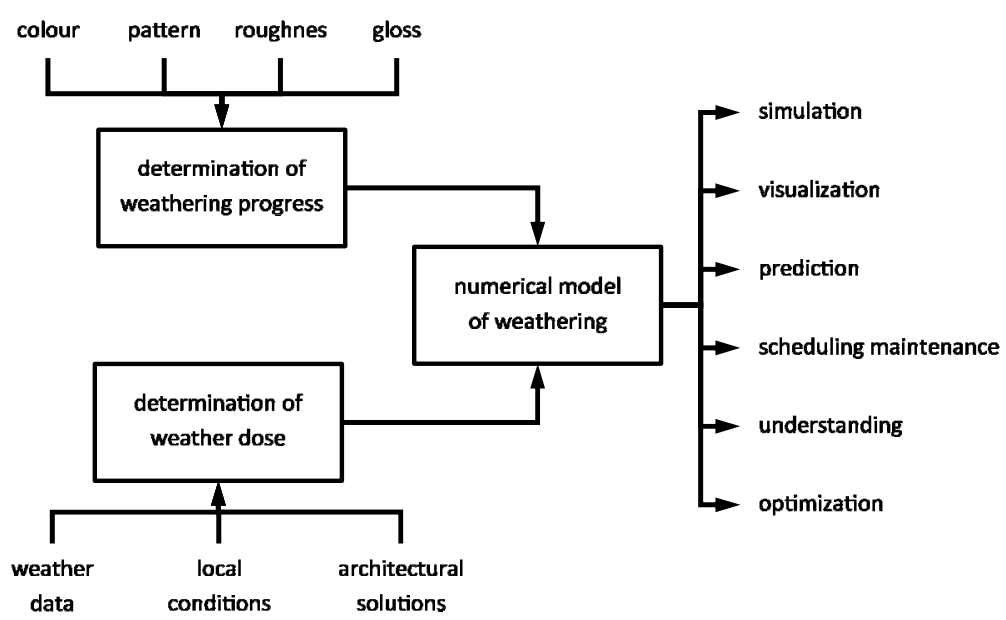

Figure 7: Development of the numerical models for bio-materials weathering. 


\section{ACKNOWLEDGEMENTS}

This work has been conducted within the Round Robin test initiative of the COST FP1006 "Bringing new functions to wood through surface modification", project BIO4ever funded within a call SIR by MIUR (RBSI14Y7Y4) and STSMs funded by COST FP1303 "Performance of Biobased building materials" and FP1407 "Understanding wood modification through an integrated scientific and environmental impact approach (ModWoodLife)".

\section{REFERENCES}

[1] Rüther, P. \& Time, B., External wood claddings - performance criteria, driving rain and large-scale water penetration methods. Wood Material Science \& Engineering, 10(3), pp. 287-299, 2016.

[2] Hovde, P.J., The Factor Method for Service Life Prediction from Theoretical Evaluation to Practical Implementation. 9DBMC International Conference on Durability of Building Materials and Components, p. 10, 2002.

[3] ISO 15686-1, Buildings and constructed assets - Service life planning. International Organization for Standardization, Geneva, Switzerland, 2011.

[4] Aagaard, N.J., Brandt, E. \& Hansen, E.J.P., Actual service life prediction of building components. XIII International Conference on Durability of Building Materials and Components - XIII DBMC, pp. 291-299, 2015. ISBN: 978-2-35158-149-0.

[5] Ebbert, T. \& Knaack, U., A flexible and upgradeable façade concept for refurbishment. Proceedings of the SB07 Lisbon - Sustainable Construction, Materials and Practices: Challenge of the Industry for the New Millennium, pp.147154, 2007.

[6] Williams, R.R., Weathering of wood. In Handbook of wood chemistry and wood composites, Rowell, R.M. (ed.) Boca Raton, CRC Press, pp. 139-185, 2005.

[7] Sandak, A., Sandak, J., Burud, I., Gobakken, L.R. \& Noël, M., Expert versus multisensor evaluation of wood samples after short term weathering. Proceedings IRG Annual Meeting, p. 11, 2016. ISSN 2000-8953, IRG/WP 16-20587.

[8] Sandak, J., Sandak, A. \& Riggio, M., Characterization and monitoring of surface weathering on exposed timber structures with multi-sensor approach. Int $J$ Archit Herit, 9(6), pp. 674-688, 2015.

[9] Casini, M., Internet of things for Energy efficiency of buildings. International Scientific Journal Architecture and Engineering, 2(1), pp. 24-28, 2014.

[10] Kurz, J.H. \& Boller, C., Some background of monitoring and NDT also useful for timber structures. Civil Struct Health Monit., 5, pp. 99-106, 2015.

[11] Hua, D., Al-Khalifa, K.N., Hamouda, A.S. \& Elsayed, E.A., Multisensor degradation data analysis. Chemical Engineering Transactions, 33, pp. 31-36, 2013.

[12] Sandak, J., Sandak, A., Pauliny, D., Riggio, M., Bonfà, S. \& Meglioli, S., A Multi Sensor Approach for Prediction of Weathering Effects on Exposed Timber Structures. Advanced Materials Research, 778, pp. 794-801, 2013.

[13] Sandak, J., Sandak, A. \& Riggio, M., Multivariate analysis of multi-sensor data for assessment of timber structures: principles and applications. Construction and Building Materials, 101(2), pp. 1172-1180, 2015.

[14] Sandak, J., Sandak, A., Hiziroglu, S. \& Bosak S., Surface Characterization of Particleboard Panels Manufactured from Eastern Redcedar Using Multi-Sensor Approach. Proceedings of International Panel Products Symposium, pp. 27-37, 2015. ISBN: 978-1-84220-136-7. 